\title{
In the moment: Does mindfulness hold the key to improving the resilience and wellbeing of pre-service teachers?
}

DOI:

10.1016/j.tate.2019.102919

\section{Document Version}

Accepted author manuscript

Link to publication record in Manchester Research Explorer

Citation for published version (APA):

Buck, R., Birchinall, E., \& Spendlove, D. (2019). In the moment: Does mindfulness hold the key to improving the resilience and wellbeing of pre-service teachers? Teaching and Teacher Education, 86, [102919].

https://doi.org/10.1016/j.tate.2019.102919

Published in:

Teaching and Teacher Education

\section{Citing this paper}

Please note that where the full-text provided on Manchester Research Explorer is the Author Accepted Manuscript or Proof version this may differ from the final Published version. If citing, it is advised that you check and use the publisher's definitive version.

\section{General rights}

Copyright and moral rights for the publications made accessible in the Research Explorer are retained by the authors and/or other copyright owners and it is a condition of accessing publications that users recognise and abide by the legal requirements associated with these rights.

\section{Takedown policy}

If you believe that this document breaches copyright please refer to the University of Manchester's Takedown Procedures [http://man.ac.uk/04Y6Bo] or contact uml.scholarlycommunications@manchester.ac.uk providing relevant details, so we can investigate your claim.

\section{OPEN ACCESS}


Title - In the moment: Does mindfulness hold the key to improving the resilience and wellbeing of pre-service teachers?

\begin{abstract}
In the English academic year 2016-17, approximately 312000 teacher days were lost due to mental ill health, at a cost of around $£ 65$ million. Stress amongst pre-service teachers is emerging as an important area of research with increasing concerns for those entering the profession. Mindfulness-based interventions (MBIs) are effective in reducing stress in multiple populations. This position piece synthesises current literature to discuss whether MBIs would be useful for stress reduction in pre-service teachers. In summary, evidence suggests that MBIs have potential to reduce stress in pre-service teachers and their inclusion should be considered in initial teacher education.
\end{abstract}

Keywords: Pre-service teachers, mindfulness, stress, anxiety well-being, MBIs (mindfulness-based interventions).

\title{
Highlights
}

- Pre-service teachers and teachers are susceptible to high levels of stress and anxiety.

- 312000 teaching days lost annually in England through teacher stress and mental health issues costing approximately $£ 65$ million.

- Substantial evidence suggests that MBIs reduce stress and anxiety 
- Evidence suggests MBIs in pre-service teacher education programmes have the potential to reduce stress and anxiety; however, there is currently a lack of highquality evidence pertaining to this specific issue.

\section{Introduction.}

In the UK, teacher absence due to mental ill health has increased from 213000 days in 2004 to approximately 312000 days in 2017 (Hassard, Teoh, Cox, \& Dewe, 2014), which equates to a financial cost of over $£ 65$ million. Parallel to these financial implications is the emotional cost to staff and pupils in terms of teacher wellbeing, pupil-teacher relationships, classroom environment and pupil outcomes (Jennings \& Greenberg, 2009). It is our contention that initial teacher education represents a critical opportunity to equip pre-service teachers with tools to support future resilience and adaptive functioning in the classroom.

This article, underpinned by a synthesis of relevant literatures, is a position piece exploring the potential utility of mindfulness-based interventions (MBIs) to reduce stress and enhance future wellbeing among pre-service teachers. We ask, "Does mindfulness hold the key to pre-service teacher wellbeing?" First, the scope of the literature employed is outlined to establish the parameters within which it is explored. Second, we explore the evidence base pertaining to stress levels among pre-service teachers. Third, we examine the potential impact of stress on retaining pre-service teachers within the profession, and why therefore, it is important to consider their wellbeing. Fourth, the concept of mindfulness is explored and documented from its emergence as an Eastern Buddhist philosophy to its more recent manifestation as a western secular meditative practice. Fifth, mechanisms of mindfulness are examined 
to establish how these theories of change may impact on stress, particularly in relation to pre-service teachers. Finally, a range of relevant studies are reviewed to establish the evidence base for the effectiveness of MBIs in reducing stress in pre-service teachers. We conclude by determining whether there is sufficient evidence for inclusion of an MBI during initial teacher education programmes to reduce stress in pre-service teachers.

\section{Scope of the Literature Synthesis.}

In recent decades, there has been an exponential growth in the investigation of mindfulness as a psychological construct and its application as a clinical and nonclinical intervention in a range of populations. This growth is mirrored in the proliferation of academic papers on the subject; zero papers published in 1980 and 842 published in 2018 (Black, 2018). Within the field of education, publications emerged at a slightly later date, with just two publications in 2002, rising to 101 in 2017 (Ergas \& Hadar, 2019). 
Figure 1. Mindfulness in education publications by year, 2002-2017 Ergas and Hadar (2019)

(with kind permission from Oren Ergas $5_{\text {th }}$ June 2019 )

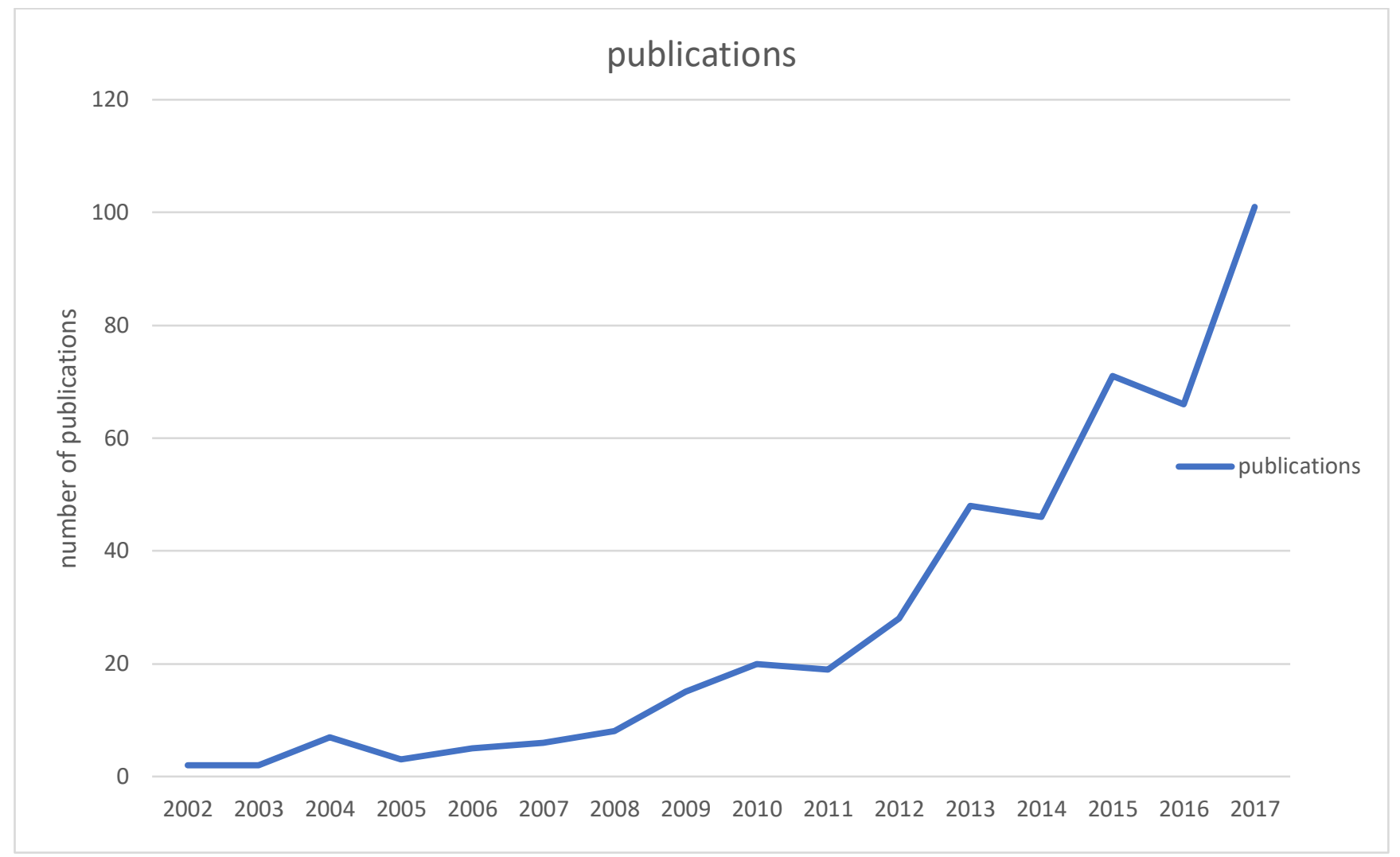

In terms of methodology, we synthesised studies from seminal authors in the field of mindfulness, mental health and education, alongside key debates and challenges within these discourses. With the exception of such key authors as John Kabat-Zinn who developed mindfulness-based stress reduction (Kabat-Zinn, 1990), and Teasdale, Segal \& Williams (1995) who developed mindfulness based cognitive behaviour therapy, date parameters were between 2002 and 2018, since few publications about mindfulness in education were available prior to these dates (Schonert-Reichl \& Roeser, 2016; Ergas \& Hadar, 2019). Studies excluded were those lacking transparency, without clear methodologies or analysis, resulting in them not being replicable or trustworthy. Limitations of these studies are described later in this paper. 


\section{Are pre-service teachers actually stressed and anxious?}

Unfortunately, stress among pre-service teachers is not particularly well researched, perhaps because it is viewed as a normal part of teacher development and accepted as a natural element of the transition from novice to a qualified teacher (Murray-Harvey, Slee, Lawson, Silins, Banfield \& Russell, 2000). It seems reasonable therefore to explore the research regarding stress in the nearest similar population, inservice teachers. Here, the evidence that teaching is stressful is well established, with the profession consistently rated as one of the top three most stressful careers (Alhija, 2015; Zurlo, Pes, \& Capasso, 2013). Identified stressors in teaching are many and include; the level of detail and duplication of tasks, the over-bureaucratic nature of the work, excessive and depth of marking, unrealistic deadlines, long or irrelevant meetings, too many sources of information to manage, poor or unreliable ICT, a lack of clarity with observation requirements, and recording, inputting monitoring and analysing data (Department for Education, 2015). In addition, it seems that teachers' repeated exposure to increasing challenges of diversification, surveillance, performativity, accountability and continual and rapid structural change may lead to increased amounts of stress (Gastaldi, Pasta, Longobardi, Prino, \& Quaglia, 2014; Gonzalez, Peters, Orange, \& Grigsby, 2017). The emergence of new challenges to teachers' authority through digital and social media also increases stress (Kyriacou \& Zuin, 2016). Contextual political pressures including a rapidly changing school system with the growth of 'academisation', changes to accountability, rapid curriculum change and increased financial pressures adds to the stressors. The increased uncertainty and workload for teachers has resulted in $76 \%$ of newly qualified teachers indicating that workload was too high and was one reason for them contemplating leaving the profession (House of Commons, 2017). 
Although research into pre-service teacher stress remains limited, indicators suggest that pre-service teacher concerns are similar to those of in-service teachers, with the addition of stress related to management of pupils, relationships and workload (Gu \& Day, 2013; Jennings, Frank, Snowberg, Coccia, \& Greenberg, 2013; Beltman, 2015). Chaplain (2008) identified that within a cohort of pre-service teachers, almost half thought being a teacher was likely to be very or extremely stressful. Hart (1987) identified four traits of anxiety particular to pre-service teachers:

- $\quad$ Evaluation anxiety - anxiety about being assessed by their class teacher, mentor or teaching practice supervisor.

- $\quad$ Pupil and professional concerns anxiety - anxiety about relationships with colleagues, preparation of teaching materials and meeting pupils' needs.

- $\quad$ Class control anxiety - anxiety about being able to manage the behaviour of pupils and general class management.

- $\quad$ Teaching practice requirements anxiety - anxiety about meeting the prescribed expectations of their teaching practice, especially paperwork and lesson plans.

From the evidence discussed it seems reasonable to suggest therefore that both in-service and pre-service teachers are stressed. It is important that protective factors are considered at the earliest stages of teachers' careers to help them to manage stress and anxiety, and maintain their wellbeing, so investigations into interventions that help mitigate against stress, such as MBIs, are worth exploring. 


\section{Impact of stress on pre-service teachers and retention.}

The retention of pre-service teachers during their training is a concern. In 2014 the average retention rates across all teacher training programmes in England varied from $48 \%-73 \%$ (Department for Education, 2016). This variation in rates depended on the training route and the pre-service teacher characteristics. In some cases, preservice teachers simply discover that teaching is not for them (House of Commons, 2017) but there is a paucity of research to establish the reasons why pre-service teachers leave their training. While issues of retention may not always correlate with stress, it is important to identify risk and protective factors at the pre-service teacher stage. Recommendations have been made to the Department for Education to engage in detailed research to establish the barriers to retention (Department for Education, 2016).

There appear to be four significant, interrelated themes relating to the recruitment and retention of new entrants to the English teaching profession:

- Attracting sufficient numbers of new teachers to the profession (House of Commons, 2017)

- $\quad$ Retaining teachers within the profession (House of Commons, 2017)

- $\quad$ Addressing teacher workloads, particularly in relation to national policy and inspection (Lynch, Worth, Bamford, \& Wespieser, 2016)

- $\quad$ Addressing and recognising teacher stress and wellbeing (Lynch et al., 2016).

It is this final point stated above, which is most pertinent and relevant to this article and underlines the importance of directly addressing this issue to improve the recruitment and retention of teachers within the profession. In a telling quote, one 
primary school teacher leaving the profession explained, "It's not a decision against teaching, it's a decision against working in this context.... the workload, the impact on my life..." (Lynch et al., 2016, p. 8). In the UK, data shows that $35 \%$ of teachers leave the profession due to stress within their first five years (House of Commons, 2017). Attrition within this 'window' is therefore a prime concern in overcoming a perception of teaching being a 'revolving door' profession with 'one in and one out' (Cooper \& Alvarado, 2006, p.5). Recognition of the significant costs associated with continually replacing teachers, is also a concern. There is now a significant strain in both attracting and supplying highly qualified and capable teachers to English schools in the numbers required.

Retention of 'in-service teachers' is also multifaceted with variability and complexity arising from regional factors, age, gender and different routes into teaching. For example, poor retention of experienced staff is changing the age profile of teachers in English schools, with the teaching workforce becoming younger (OECD, 2017). Only $48 \%$ of teachers in English secondary schools have over 10 years' experience compared with an average of $64 \%$ in other countries (House of Commons, 2017). This changing demographic indicates that newly qualified teachers and pre-service teachers have fewer experienced colleagues to call upon and are more likely to occupy demanding leadership positions early in their career, which could impact on lack of support and increased stress. Chaplain (2008) suggests that stress is a powerful predictor for teacher retention and that self-efficacy, emotional awareness, and resilience are also closely linked to pre-service teachers' intention to leave their teacher training programmes (Pfitzner-Eden, 2016). Clearly, teaching is a challenging and demanding career which has an impact on the retention of teachers. 
Turner, Braine, \& College (2016) describe the importance of pre-service teachers "needing to look after themselves" (p.67) to reduce burnout, improve retention, and develop positive teacher-pupil relationships and outcomes. A strong case is therefore developing to equip pre-service teachers at the earliest stages of their career with the appropriate skills to increase resilience and bring the social physical and mental aspects of their wellbeing into alignment. Our position in this paper is one of concern about pre-service teachers' wellbeing in both supporting them in their training but also providing a foundation for their future career as they bridge the transition between preservice to in-service teacher. Hence, we explore mindfulness practice as one developing field with the potential to address this stress.

\section{What is mindfulness?}

Mindfulness is a contemplative practice based in Buddhist traditions (Thera, 2005). During the 1950s there was a growth of spiritual and meditative practices in the western world, leading to the introduction of these techniques into psychotherapy (Boss, 1965; Fingarette, 1963). In the late 1970s mindfulness developed as a psychological construct and was applied as a clinical intervention. Secular western versions of mindfulness-based practice emerged in the 1980 s, mostly relating to medicine, but were soon applied to other disciplines and professions including psychology and education (Baer, Smith, Hopkins, Krietemeyer, \& Toney, 2006; Williams \& Kabat-Zinn, 2011). The seminal definition of mindfulness frequently applied in contemporary research is "Paying attention in a particular way: on purpose, in the present moment and nonjudgmentally" (Kabat-Zinn, 1994, p. 4). 
The secular approach, embodied within mindfulness-based interventions is often characterized by daily meditations to reach a state of awareness of the present moment (Kabat-Zinn et al., 1998; Shapiro, Schwartz, \& Bonner, 1998). In our normal daily lives we engage with a constant stream of thoughts in an effort to solve problems, make decisions, or choose behaviours (Bodhi, 1984), however, 'over-thinking' can result in rumination and worry. One important aim of mindfulness is to avoid the worry or rumination associated with an event or issue (Gunaratana, 2001). The contemplative approach to mindfulness links practice to the philosophical Buddhist traits of compassion; developing attitudes of empathy and loving kindness for oneself (Cullen, 2011). It is argued that when contemplative approaches to mindfulness in education are used, there are improvements in teachers' social and emotional competence and wellbeing, thus creating the 'pro-social' classroom with improvements in relationships with pupils, classroom management, ethos, atmosphere, and pupil outcomes (Roeser, 2016; Jennings \& Greenberg, 2009). A criticism of separating the secular and more traditional contemplative domains of mindfulness, is the danger that there will be a reduction in its power to be transformative. Instead, mindfulness becomes a stress reduction commodity with no genuine meaning, removed from its ethical foundations (Cullen, 2011; Hyland, 2017). 


\section{Mindfulness and education.}

Ergas \& Hadar (2019) describe the practice and understanding of mindfulness within the field of education to be complex and disparate, drawing on both the secular and contemplative domains. Ergas and Hadar (2019) identified two main strands:

a) Mindfulness in education: which comprises mostly outsourced, secularized interventions aimed at improved mental-physical health, social-emotional learning and cognitive functions.

b) Mindfulness as education: which is a more transformative strand characterized by contemplative pedagogy in higher education and sporadic whole-school implementations.

(Ergas and Hadar, 2019, p.86)

In this paper we are using the frame of mindfulness in education. It is through this lens that we explore the value of secular mindfulness-based interventions for preservice teachers aimed at reducing their stress and anxiety. There are two main mindfulness-based intervention programmes designed for general populations, Mindfulness-based stress reduction MBSR (Kabat-Zinn, 1990) and Mindfulness based cognitive behaviour therapy MBCT (Segal, Williams and Teasdale 2018). MBSR and MBCT are both intensive eight-week programmes. Mindfulness based cognitive behaviour therapy (MBCT) is an intervention which lies mainly within the therapeutic domain. There is a lack of evidence supporting the use and effectiveness of MBCT in education settings, so for this reason it has been omitted from this article. 
Mindfulness-based stress reduction (MBSR) is a manualised treatment programme for chronic pain and is recognised as being responsible for the rise of interest in clinical applications of mindfulness (Bishop, Lau, Shapiro, Carlson, Anderson, Carmody, Segal, Buis, Abbey \& Devins, 2004). It was the first MBI to be clinically evaluated and successfully demonstrate its efficacy (Kabat-Zinn, 2017; Kabat-Zinn, Lipworth \& Burnley, 1985). The MBSR manual contains detailed instruction for the formal practices of the body scan, sitting meditation and mindful movement (Kabat-Zinn, 2017). MBSR aims to be more than simply a stress reduction programme by incorporating mindful behaviour throughout participants' lives. It claims a range of potential benefits including improved wellbeing, through reducing unhelpful ways of thinking, worry or rumination and the associated feelings of stress and anxiety. It suggests that through reducing automated thinking and behaviours, it allows the participant to select better choices, thus improving self-regulation and consequently their wellbeing (Dimidjian \& Linehan, 2003; Kabat-Zinn et al., 1998; Segal, Williams, \& Teasdale, 2002; Teasdale, 1999) An MBI is just one such tool which may reduce stress and improve well-being. It is important therefore that we fully understand how it works. These theoretical mechanisms of how MBSR reduces stress and anxiety are explored in more detail below.

\section{Mechanisms of mindfulness.}

During mindfulness practice, an individual can distance themselves from their thoughts by 'just noticing' them as they 'come and go'. By distancing themselves from their thoughts and disengaging from the associated emotions, stress and anxiety are reduced (Teasdale, Segal, Williams, Ridgeway, Soulsby, \& Lau, 2000). This shift in 
perspective of 'noticing' and 'not engaging' with thoughts appears to be the key change mechanism in mindfulness and is sometimes called 'reperceiving' or 'de-centering' (Bohlmeijer, Klooster, Fledderus, Veehof, \& Baer, 2011). During the re-perceiving of your thoughts there is a shift in perspective so that you dis-identify from your thoughts and experience the present moment more clearly and objectively (Shapiro, Carlson, Astin \& Freedman, 2006). De-centering involves changing one's awareness of thoughts for example;

- Metacognitive knowledge - knowing that thoughts are not always true or accurate ("thoughts are not facts and I am not my thoughts") (Teasdale, 1999)

- Metacognitive insight - knowing that thoughts 'come and go' rather than being direct readouts on reality (Teasdale, 1999, p. 146)

- De-automatization - disengaging from 'automatic pilot' (Deikman, 1982; Safran \& Segal, 1990).

Cognitive reactivity $(\mathrm{CR})$ such as rumination and worry are linked to the unhelpful tendencies of avoiding, suppressing or over-engaging with distressing thoughts and emotions (Hayes \& Feldman, 2004). These unhelpful tendencies can cause subsequent emotional reactivity (ER) in the form of stress and anxiety. These behaviours could be considered the opposite of mindfulness' core concepts of 'attention to' and 'non-judgmental awareness of' one's current experiences. There is strong and consistent evidence that the mechanisms of mindfulness operate to alleviate stress and anxiety caused by rumination and worry (Gu, Strauss, Bond, \& Cavanagh, 2015). Bohlmeijer et al., (2011) suggest that individuals who reduce their identification with thoughts, feelings and emotions through mindfulness meditation improve their self- 
regulation, make better behavioural choices and consequently improve their wellbeing (Keng, Smoski, \& Robins, 2011; Oberle, Schonert-Reichl, Lawlor, \& Thomson, 2012).

According to the mechanisms described above, it seems reasonable to suggest that mindfulness practice could reduce stress experienced by pre-service teachers by distancing them from their thoughts and associated emotions. In this way their selfregulation of emotions increases, enabling them to choose more helpful thoughts and behaviours for dealing with the stress. MBIs could therefore be classed as 'teacher education' supporting the development of healthy 'habits of mind,' improving emotional regulation and reducing stress (Roeser, Skinner, Beers, \& Jennings, 2012).

There are two logic models which describe the mechanism of mindfulness and outline the theory of change during practice (see fig 2 and 3 below). First, Roeser, Schonert-Reichl, Kimberly, Cullen, Wallace, Wilensky, Oberle, Thomson, Taylor \& Harrison (2013) suggest that participants engaged in an MBI improve their mindfulness and self-compassion. Next their levels of stress, anxiety, depression and burnout reduce. As a consequence of these changes their coping and resilience increases. This results in teachers having more energy which is re-directed into their teaching, producing positive outcomes for pupils. 
Figure 2 Theory of change in mindfulness Roeser et al., (2013)

\begin{tabular}{|l|}
\hline - engagement in MBI \\
\hline \hline - improves teachers' mindfulness and self compassion \\
\hline \hline - teachers'stress, anxiety, depression and burnout reduces \\
\hline \hline - teachers coping skills and resilience improve \\
\hline \hline - teachers conserve energy \\
\hline
\end{tabular}

Second, Jennings \& Greenberg (2009) suggest a mechanism of change for an MBI, based on their model of the 'prosocial classroom.' This model suggests that by engaging in an MBI, teachers are able to regulate their attention through 'de-centering' their thoughts and increasing their self-awareness. As self-awareness increases, so does self-compassion, and this enhances their emotional regulation and thus reduces stress. Interestingly they also propose that there is a reciprocal relationship between emotional regulation and self-efficacy with mutually beneficial and reciprocal outcomes for both teachers and students. In this model teachers are then better able to focus their energy on teaching, and thus improve the quality of lessons and potentially student outcomes.

Figure 3 Proposed mechanism of mindfulness Jennings and Greenberg (2009)

\begin{tabular}{|l|}
\hline$\bullet$ engagement in $\mathrm{MBI}$ \\
\hline •decentering, self awareness, regulation of attention, self compassion \\
\hline •enhanced emotional regulation \\
\hline - increased teacher self efficacy
\end{tabular}


Using these suggested mechanisms for mindfulness, the effectiveness of such programmes now needs to be examined to explore their efficacy as a potential tool to reduce stress in pre-service teachers.

\section{Evidence for the effectiveness of MBIs in reducing stress and anxiety.}

Original research in mindfulness focused on the effectiveness of medical applications of mindfulness in clinical populations. The subsequent application of MBIs in general populations also found that they are effective treatments for a range of psychological problems, being particularly effective in reducing anxiety, stress and depression (Shapiro et al., 1998). Likewise, there are a range of positive outcomes recorded for 'non-clinical' populations such as professionals engaging in MBIs including; stress, anxiety, wellbeing, performance and self-regulation (Eby, Allen, Conley, Williamson, Henderson, \& Mancini, 2019).

The more recent and increasing body of research regarding mindfulness within the education domain, suggests positive benefits in stress reduction and improving wellbeing for 'in-service' teachers and a small body of evidence for 'pre-service' teachers (Ergas and Hadar, 2019). The findings for the effectiveness of MBIs within in-service and pre-service populations is now explored in more detail.

\section{Evidence from in-service teachers.}

Evidence from a wide range of studies with 'in-service' teachers suggests that mindfulness-based interventions have a positive impact on the mental health and wellbeing of teachers. For example, in a systematic review involving 1981 educators, 
(Lomas, Medina, Ivtzan, Rupprecht, \& Eiroa-Orosa, 2017) found positive outcomes for a wide range of measures including wellbeing, stress, burnout, anxiety, self-regulation, depression, distress tolerance, mindfulness and time pressure. A systematic review by (Hwang, Bartlett, Greben, \& Hand, 2017) involving mindfulness based interventions with over 600 educators found similar positive outcomes with MBIs being effective in reducing teacher stress, anxiety burnout and depression and thus improving teacher wellbeing. Ergas and Hadar (2019) explored over 447 peer reviewed papers about mindfulness in education between 2002 and 2017, noting its main aim was to improve wellbeing and mental health and that its implementation in these settings has grown to to such an extent that mindfulness is now becoming more 'mainstream' rather than an extra-curricular opportunity. These results have been mirrored in other studies with MBIs recording benefits for teachers including; reduction in stress, anxiety, depression and burnout and thus an improvement in wellbeing (Paquette \& Rieg, 2016; Meiklejohn, Philips, Freedman, Griffin, Biegel, Roach, Frank, Burke, Pinger, Soloway, Isberg, Sinbinga, Grossman \& Saltzman, 2012; Flook, Goldberg, Pinger, Bonus \& Davidson, 2013). Other positive outcomes include increases in mindfulness, selfcompassion and emotional self-regulation (Emerson, Leyland, Hudson, Rowse, Hanley, \& Hugh-Jones, 2017; Hwang et al., 2017). Interestingly, as emotional regulation increases so does teacher self-efficacy, suggesting that this is a reciprocal relationship (Reiser \& McCarthy, 2018). Jennings, Brown, Joshua, Frank, Jennifer, Doyle, Sabrina, Oh, Yoonkyung, Davis, Regin, Rasheed, Damira, DeWeese, Anna, DeMauro, Anthony, Cham, Heining \& Greenberg (2017) report statistically significant positive effects of an MBI on adaptive emotion regulation, mindfulness, psychological distress, and time urgency. Also noted was the development of 'healthy habits of mind' and compassion in teaching (Ergas and Hadar, 2019). 


\section{Evidence from pre-service teachers.}

Studies describing the utility of MBIs as a tool for reducing stress with preservice teachers are largely absent from rigorous empirical studies (Klassen \& Durksen, 2014; Paquette \& Rieg, 2016; Vesely, Saklofske, \& Nordstokke, 2014). However, positive outcomes for promoting wellbeing, managing stress and avoiding burnout were evident in a number of studies (Bernay, 2014; Hue \& Lau, 2015). Additional benefits identified included; improvements in stress, depression, anxiety, sleep quality, physical health, and interpersonal relationship quality, greater emotional clarity, improved selfregulation (Kerr, Lucas, Didomenico, Mishra, Stanton, Shivde, Pero, Runven \& Terry, 2017). Bernay (2014) demonstrated that pre-service teachers engaged in an MBI 'responded' rather than 'reacted emotionally' to pupils' needs and suggest its use in teacher education could support pre-service teacher wellbeing and potentially job retention. Kerr et al., (2017) concur, indicating that mindfulness practices can enhance emotion regulation skills and cultivate emotional well-being. Pre-service teachers found mindfulness both enjoyable and useful and thought that it could be beneficial for themselves and their pupils (Beers Dewhirst \& Goldman, 2018). Albrecht (2018) recommends mindfulness is provided for both in-service and pre-service teacher to reduce stress and burnout but also to provide them with skills to pass onto their own pupils. From both the small amount of evidence related to pre-service teachers, alongside the larger body of evidence relating to the nearest similar population of 'inservice teachers' it would seem reasonable to consider MBIs as potentially beneficial during initial teacher educations programmes, to reduce stress and anxiety. 


\section{Potential moderators in MBIs}

\section{Length and dosage.}

Studies show considerable variability in the type, length and dosage of MBIs with varying results (Dunning, Griffiths, Kuyken, Crane, Foulkes, Parker, \& Dalgleish, 2018; Gu et al., 2015). On the one hand, MBIs with longer and more frequent mindfulness sessions, higher attendance and homework practice, have demonstrated larger reductions in stress (Gotink, Chu, Busschbach, Benson, Fricchione \& Hunink, 2015; Zenner, Herrnleben-Kurz, \& Walach, 2014). Conversely, abbreviated forms of MBIs appear to be yielding positive outcomes too. O'Driscoll, Byrne, Mc Gillicuddy, Lambert, \& Sahm's review (2017) evidences short-term improvements to stress, mood and mindfulness levels despite all but one study using shorter MBIs. Baer, Carmody, \& Hunsinger (2012) concur, finding no significant association between the length of mindfulness sessions and positive psychological outcomes. Khoury, Sharma, Rush, \& Fournier (2015) found that even with variation in the length of sessions, practice time and other protocols, moderate effects were still found for a MBSR intervention. Thus, all forms of MBIs have the potential to reduce stress, supporting the notion of an abbreviated form of MBI working effectively (Burton, Burgess, Dean, Koutsopoulou, \& Hugh-Jones, 2017). Collectively, these studies evidence the potentially positive outcomes for low dosage, informal mindfulness practices among professional populations, who are prohibited through time and circumstance from committing to traditional intensive eight-week programmes, such as MBSR. This is relevant to our considerations for this paper, as pre-service teachers involved in an intensive teacher education programme are 'time poor' and so length and dosage would need to be a consideration in the planning and delivery of an MBI with this group. Interestingly, Baer, (2003) found many participants who started MBIs completed them, in spite of 
demands of additional workload such as homework, and some groups continued the mindfulness practice once the programme had ended. This suggests that even among the busiest populations, those who prioritise mindfulness training are able to complete it. Amongst teachers who participated in a mindfulness-based professional development programme, Jennings et al., (2017) found lower levels of time urgency, the need to talk fast, eat quickly, and both task-related and general hurry. Considering that effective mindfulness training during pre-service training could positively impact on the pre-service teachers, the pupils and consequently the school's teaching and ethos, it is important to address concerns regarding the sustainability of the varied dosages models (Ergas \& Hadar, 2019). Burton et al., (2017) recommend further research into dosage would be useful and so our research into this area is timely, adding to this developing body of knowledge.

\section{Sustainability.}

Regarding retention post mindfulness intervention, a number of studies provide some positive indicators of longer-term benefits (Khoury, Lecomte, Fortin, Masse, Therien, Bouchard, Chapleau, Paquin \& Hofmann, 2013; Miller, Fletcher \& KabatZinn, 1995). However, caution should be applied to these findings as they were predominantly situated within the medical arena and measured other traits in addition to stress and anxiety, such as pain management. In contrast, O’Driscoll et al., (2017) reported no sustained outcomes from a study of MBIs with health and social care undergraduate students. These findings were mirrored by Emerson et al., (2017), who reported little or no sustained effects at follow up points from MBIs measuring reduced stress as an outcome with teachers. However, Hwang et al., (2017) found sustainable outcomes for teacher wellbeing and performance at follow-ups from 4 out of 16 reports 
but suggest that sustained affects could not be expected without ongoing mindfulness practice. When measures included the trait of mindfulness itself, findings showed participants were more mindful at the end of the treatment period with higher gains at the final follow up time, correlating with the clinical outcomes described above (Khoury et al., 2015). Although studies exploring MBIs involving larger groups of schools and teachers are now becoming broader, (for example, Jennings et al., (2017) investigating an MBI involving 36 urban elementary schools and 224 teachers), a gap in the literature remains regarding the area of retention post mindfulness intervention in education, so this would be an area worthy of further research.

\section{Limitations of the studies on MBIs.}

In assessing the outcomes of the research evidence into MBIs, it is important to be clear about their quality, reliability and trustworthiness (Evans \& Benefield, 2001). Regardless of the significant numbers of MBI studies over the last 10 years, many are of low quality (Emerson et al., 2017), with small sample sizes a common problematic feature. Future research should ensure samples are large enough to detect smaller effects one might expect to see in non-clinical populations (Baer, 2003; Emerson et al., 2017). Other common features of low quality studies included variability in context, design and a lack of active controls (Zenner et al., 2014). Other omissions include; implementer training and fidelity testing (Baer, 2003). The potential for publication bias exists for small studies with small effect sizes, reducing the likelihood of them being published (Emerson et al., 2017; Gu et al., 2015). More recently, in response to the criticism regarding the poor methodological quality of many mindfulness studies, Goldberg, Tucker, Greene, Simpson, Kearney \& Davidson (2017) reported more positive developments in this area. In a meta-analysis reviewing 142 studies they described an upward trajectory in terms of improving quality including improvements 
in sample size, fidelity testing and the reporting of intent to treat analyses, particularly in UK and USA studies.

\section{Conclusions}

Pre-service teacher stress and wellbeing is a theme that is largely absent from rigorous empirical studies in relation to both problematising and addressing what is deemed a stressful period of training (Klassen \& Durksen, 2014; Paquette \& Rieg, 2016; Vesely et al., 2014) The available evidence discussed in this article supports the notion that both pre-service teachers and in-service teachers are indeed stressed. Teacher retention data suggests that this stress has an impact on health with high rates of teacher absence. Consequently, retaining teachers in the profession is a challenge. There is a financial, emotional and educative cost to schools, teachers and pupils as a consequence of high absenteeism and low teacher retention. The stressors on teachers are multi-faceted including aspects of the job itself and teachers' own emotional and behavioural responses to the challenges. In addition, schools' own systems and practices, designed in response to external accountability and responsibility, create systemic pressure adding additional stress to teachers.

Could MBIs be effective in reducing stress and anxiety in pre-service teachers? Literature regarding research into the utility of MBIs as a potential tool for reducing stress and anxiety in this population is sparse. Drawing on the positive outcomes in the available literature with the nearest population of 'in-service' teachers discussed, alongside the few studies of pre-service teachers,' it is appropriate to hypothesise that an MBI for pre-service teachers could be beneficial. Our synthesis confirms that the key potential benefits of an MBI for pre-service teachers would be to reduce stress and anxiety and increase mindfulness, self-regulation and teacher self-efficacy. 
In summary, the evidence from this literature synthesis indicates consistently positive outcomes for stress and anxiety reduction through a range of different MBIs, thus providing a strong rationale for delivering and evaluating such a programme within teacher education. Ultimately, we see programmes such as this in pre-service teacher preparation as just one aspect of a range of initiatives that need to be considered to aid teacher supply and retention. We acknowledge that whilst trying to develop strategies to enhance pre-service teachers' wellbeing, systemic factors related to workload and teacher burnout are left unaddressed. However, MBIs may enable pre-service teachers to more effectively navigate this stressful occupation until such time as these factors are dealt with via professional and political reform.

A two-pronged approach is necessary. First, there is a need to nurture our preservice teachers by providing them with tools to cope with the pressure of choosing a career deemed stressful. We need to do this by continuing to research the causes of stress and researching effective tools to combat this, one of which may be mindfulness. Second, we need to address the systemic factors which increase workload and lead to teacher burnout by participating in professional consultations, through both political and professional channels, to mitigate the pressures and stressors currently associated with the job. Alongside this, high quality teacher education programmes would ensure that future generations of teachers can teach and support pupils effectively so that neither become discouraged or disadvantaged.

5335 words 


\section{Bibliography}

Albrecht, N. J. (2018). Teaching mindfulness with children: Being a Mindful Role Model. Australian Journal of Teacher Education, 43(10), 1-23. https://doi.org/10.14221/ajte.v43.n10.1

Alhija, F. N.-A. (2015). Teacher Stress and Coping: The Role of Personal and Job Characteristics. Procedia - Social and Behavioral Sciences, 185, 374-380. https://doi.org/10.1016/j.sbspro.2015.03.415

Baer, R. A. (2003). Mindfulness training as a clinical intervention: A conceptual and empirical review. Clinical Psychology: Science and Practice, 10(2), 125-143. https://doi.org/10.1093/clipsy/bpg015

Baer, R. A., Smith, G. T., Hopkins, J., Krietemeyer, J., \& Toney, L. (2006). Using selfreport assessment methods to explore facets of mindfulness. Assessment, 13(1), 27-45. https://doi.org/10.1177/1073191105283504

Baer, R. A., Carmody, J., \& Hunsinger, M. (2012). Weekly Change in Mindfulness and Perceived Stress in a Mindfulness-Based Stress Reduction Program. Journal of Clinical Psychology, 68(7), 755-765. https://doi.org/10.1002/jclp.21865

Beers Dewhirst, C., \& Goldman, J. (2018). Launching motivation for mindfulness: introducing mindfulness to early childhood preservice teachers. Early Child Development and Care, $\quad O(0), \quad 1-14$. https://doi.org/10.1080/03004430.2018.1531853

Beltman, S. (2015). Teacher professional resilience: Thriving not just surviving. Learning to teach in the secondary school, 20-38. Cambridge University Press.

Bernay, R. (2014). Mindfulness and the beginning teacher. Australian Journal of Teacher Education, 39(7), 58-69. https://doi.org/10.14221/ajte.2014v39n7.6 
Bishop, S. R., Lau, M., Shapiro, S., Carlson, L., Anderson, N. D., Carmody, J., ... Devins, G. (2004). Mindfulness: A proposed operational definition. Clinical Psychology: Science and Practice, 11(3), 230-241. https://doi.org/10.1093/clipsy/bph077

Bodhi, B. (1984). The noble eightfold path (p. 63). Kandy, Sri Lanka: Buddhist Publication Society.

Bohlmeijer, E., Klooster, P. M., Fledderus, M., Veehof, M., \& Baer, R. (2011). Psychometric properties of the five facet mindfulness questionnaire in depressed adults and development of a short form. Assessment, 18(3), 308-320. https://doi.org/10.1177/1073191111408231

Boss, M. (1965). A psychiatrist discovers India. Wolff.

Black, D. S. (2018) Mindfulness journal publications by year, 1980-2018. Retrieved from: https://goamra.org/ resources/

Burton, A., Burgess, C., Dean, S., Koutsopoulou, G. Z., \& Hugh-Jones, S. (2017). How Effective are Mindfulness-Based Interventions for Reducing Stress Among Healthcare Professionals? A Systematic Review and Meta-Analysis. Stress and Health, 33(1), 3-13. https://doi.org/10.1002/smi.2673

Chaplain, R. P. (2008). Stress and psychological distress among trainee secondary teachers in England. Educational Psychology, 28(2), 195-209.

Cooper, J. M., \& Alvarado, A. (2006). Preparing, recruiting and retention of teachers. International Institute for Educational Planning, 5, 26.

Cullen, M. (2011). Mindfulness-Based Interventions: An Emerging Phenomenon. Mindfulness, 2(3), 186-193. https://doi.org/10.1007/s12671-011-0058-1

Deikman, A. J. (1982). The observing self: Mysticism and psychotherapy. Beacon Press. 
Department for Education. 2015. Workload Challenge: Analysis of teacher consultation responses.

Retrieved

from https://www.gov.uk/government/publications/workload-challenge-analysis-ofteacher-responses

Department for Education. 2016. Linking ITT and workforce data: (Initial Teacher Training Performance Profiles and School Workforce Census) Retrieved from https://www.gov.uk/government/publications/linking-itt-and-workforce-datainitial-teacher-training-performance-profiles-and-school-workforce-census

Dimidjian, S., \& Linehan, M. M. (2003). Defining an agenda for future research on the clinical application of mindfulness practice. Clinical Psychology: Science and Practice, 10(2), 166-171. https://doi.org/10.1093/clipsy/bpg019

Dunning, D. L., Griffiths, K., Kuyken, W., Crane, C., Foulkes, L., Parker, J., \& Dalgleish, T. (2019). Research Review: The effects of mindfulness-based interventions on cognition and mental health in children and adolescents - a metaanalysis of randomized controlled trials. Journal of Child Psychology and Psychiatry and Allied Disciplines, 60(3), 244-258. https://doi.org/10.1111/jcpp.12980

Eby, L. T., Allen, T. D., Conley, K. M., Williamson, R. L., Henderson, T. G., \& Mancini, V. S. (2019). Mindfulness-based training interventions for employees: A qualitative review of the literature. Human Resource Management Review, 29(2), 156-178. https://doi.org/10.1016/j.hrmr.2017.03.004

Emerson, L. M., Leyland, A., Hudson, K., Rowse, G., Hanley, P., \& Hugh-Jones, S. (2017). Teaching Mindfulness to Teachers: a Systematic Review and Narrative Synthesis. Mindfulness, 8(5), 1136-1149. https://doi.org/10.1007/s12671-0170691-4 
Ergas, O., \& Hadar, L. L. (2019). Mindfulness in and as education: A map of a developing academic discourse from 2002 to 2017. Review of Education, 1-63. https://doi.org/10.1002/rev3.3169

Evans, J., \& Benefield, P. (2001). Systematic Reviews of Educational Research : does the medical model t?,27(5). https://doi.org/10.1080/0141192012009571

Fingarette, H. (1963). The self in transformation: Psychoanalysis, philosophy and the life of the spirit, Oxford, England: Basic Books.

Flook, L., Goldberg, S. B., Pinger, L., Bonus, K., \& Davidson, R. J. (2013). Mindfulness for teachers: A pilot study to assess effects on stress, burnout, and teaching efficacy. Mind, Brain, and Education, 7(3), 182-195.

Gastaldi, F. G. M., Pasta, T., Longobardi, C., Prino, L. E., \& Quaglia, R. (2014). Measuring the influence of stress and burnout in teacher-child relationship. European Journal of Education and Psychology, 7(1), 17-28. https://doi.org/10.1989/ejep.v7i1.149

Goldberg, S. B., Tucker, R. P., Greene, P. A., Simpson, T. L., Kearney, D. J., \& Davidson, R. J. (2017). Is mindfulness research methodology improving over time? A systematic review. PLoS ONE, 12(10), 1-16. https://doi.org/10.1371/journal.pone.0187298

Gonzalez, A., Peters, M. L., Orange, A., \& Grigsby, B. (2017). The influence of highstakes testing on teacher self-efficacy and job-related stress. Cambridge Journal of Education, 47(4), 513-531. https://doi.org/10.1080/0305764X.2016.1214237

Gotink, R. A., Chu, P., Busschbach, J. J. V., Benson, H., Fricchione, G. L., \& Hunink, M. G. M. (2015). Standardised mindfulness-based interventions in healthcare: An overview of systematic reviews and meta-analyses of RCTs. PLOS ONE, 10(4), 117. https://doi.org/10.1371/journal.pone.0124344 
Gu, J., Strauss, C., Bond, R., \& Cavanagh, K. (2015). How do mindfulness-based cognitive therapy and mindfulness-based stress reduction improve mental health and wellbeing? A systematic review and meta-analysis of mediation studies. Clinical Psychology Review, 37, 1-12. https://doi.org/10.1016/j.cpr.2015.01.006

Gu, Q., \& Day, C. (2013). Challenges to teacher resilience: Conditions count. British Educational Research Journal, $\quad 39(1), \quad$ 22-44. https://doi.org/10.1080/01411926.2011.623152

Gunaratana, H. (2001). Eight mindful steps to happiness: Walking the Buddha's path. retrieved from Simon and Schuster.com, 2011, ISBN 0861719204, 9780861719204

Hart, N., I. (1987). Student teacher anxieties: four measured factors and their relationships to pupil disruption in class. Educational Research, 29, 12-18.

Hassard, J., Teoh, K., Cox, T., \& Dewe, P. (2014). Calculating the cost of work-related stress and psychosocial risks: European Risk Observatory Literature Review. European Agency for Safety and Health at Work. https://doi.org/10.2802/20493

Hayes, A. M., \& Feldman, G. (2004). Clarifying the construct of mindfulness in the context of emotion regulation and the process of change in therapy. Clinical Psychology: Science and Practice, 11(3), 255-262. https://doi.org/10.1093/clipsy/bph080

House of Commons Education Committee. 2017. Recruitment and retention of teachers: (Fifth Report of Session 2016-17). Retrieved from http://dera.ioe.ac.uk/id/eprint/28384.

Hue, M. T., \& Lau, N. S. (2015). Promoting well-being and preventing burnout in teacher education: a pilot study of a mindfulness-based programme for pre-service teachers in Hong Kong. Teacher Development, 19(3), 381-401. 
https://doi.org/10.1080/13664530.2015.1049748

Hwang, Y. S., Bartlett, B., Greben, M., \& Hand, K. (2017). A systematic review of mindfulness interventions for in-service teachers: A tool to enhance teacher wellbeing and performance. Teaching and Teacher Education, 64, 26-42. https://doi.org/10.1016/j.tate.2017.01.015

Hyland, T. (2017). McDonaldizing Spirituality: Mindfulness, Education, and Consumerism. Journal of Transformative Education, 15(4), 334-356. https://doi.org/10.1177/1541344617696972

Jennings, P. A., \& Greenberg, M. T. (2009). The Prosocial Classroom: Teacher Social and Emotional Competence in Relation to Student and Classroom Outcomes. Review of Educational Research, 79(1), 491-525. https://doi.org/10.3102/0034654308325693

Jennings, Patricia A., Brown, J. L., Frank, J. L., Doyle, S., Oh, Y., Davis, R., ... Greenberg, M. T. (2017). Impacts of the CARE for teachers program on teachers' social and emotional competence and classroom interactions. Journal of Educational Psychology, 109(7), 1010-1028. https://doi.org/10.1037/edu0000187

Jennings, Patricia A., Frank, J. L., Snowberg, K. E., Coccia, M. A., \& Greenberg, M. T. (2013). Improving classroom learning environments by cultivating awareness and resilience in education (CARE): Results of a randomized controlled trial. School Psychology $\quad$ Quarterly, 28(4), 374-390. https://doi.org/10.1037/spq0000035

Kabat-Zinn, J., Lipworth, L., \& Burney, R. (1985). The clinical use of mindfulness meditation for the self-regulation of chronic pain. Journal of behavioral medicine, 8(2), 163-190.

Kabat-Zinn, J. (1990). University of Massachusetts Medical Center/Worcester. Stress 
Reduction Clinic. Full catastrophe living: using the wisdom of your body and mind to face stress, pain, and illness. Pain, and Illness (New York: Delta, 1991).

Kabat-Zinn, J. (1994). Wherever you go. There you are: mindfulness meditation in everyday life. Hatchette Books.

Kabat-Zinn, J., Wheeler, E., Light, T., Skillings, A., Scharf, M. J., Cropley, T. G., ... Bernhard, J. D. (1998). Influence of a mindfulness meditation-based stress reduction intervention on rates of skin clearing in patients with moderate to severe psoriasis undergoing phototherapy (UVB) and photochemotherapy (PUVA). Psychosomatic Medicine, 60(5), 625-632. https://doi.org/10.1097/00006842199809000-00020

Kabat-Zinn. (2017). MBSR Curriculum. Retrieved from https://www.umassmed.edu/globalassets/center-formindfulness/documents/mbsr-curriculum-guide-2017.pdf

Keng, S. L., Smoski, M. J., \& Robins, C. J. (2011). Effects of mindfulness on psychological health: A review of empirical studies. Clinical Psychology Review, 31(6), 1041-1056. https://doi.org/10.1016/j.cpr.2011.04.006

Kerr, S. L., Lucas, L. J., DiDomenico, G. E., Mishra, V., Stanton, B. J., Shivde, G., ... Terry, G. M. (2017). Is mindfulness training useful for pre-service teachers? An exploratory investigation*. Teaching Education, 28(4), 349-359. https://doi.org/10.1080/10476210.2017.1296831

Khoury, B., Lecomte, T., Fortin, G., Masse, M., Therien, P., Bouchard, V., ... Hofmann, S. G. (2013). Mindfulness-based therapy: A comprehensive metaanalysis. Clinical Psychology Review, 33(6), 763-771. https://doi.org/10.1016/j.cpr.2013.05.005

Khoury, B., Sharma, M., Rush, S. E., \& Fournier, C. (2015). Mindfulness-based stress 
reduction for healthy individuals: A meta-analysis. Journal of Psychosomatic Research, 78(6), 519-528. https://doi.org/10.1016/j.jpsychores.2015.03.009

Klassen, R. M., \& Durksen, T. L. (2014). Weekly self-efficacy and work stress during the teaching practicum: A mixed methods study. Learning and Instruction, 33, 158-169. https://doi.org/10.1016/j.learninstruc.2014.05.003

Kyriacou, C., \& Zuin, A. (2016). Cyberbullying of teachers by students on YouTube: challenging the image of teacher authority in the digital age. Research Papers in Education, 31(3), 255-273. https://doi.org/10.1080/02671522.2015.1037337

Lomas, T., Medina, J. C., Ivtzan, I., Rupprecht, S., \& Eiroa-Orosa, F. J. (2017). The impact of mindfulness on the wellbeing and performance of educators: A systematic review of the empirical literature. Teaching and Teacher Education, 61, 132-141. https://doi.org/10.1016/j.tate.2016.10.008

Lynch, S., Worth, S., Bamford, J., \& Wespieser, S. (2016). Engaging Teachers: NFER Analysis of Teacher Retention, 1-26.

Meiklejohn, J., Phillips, C., Freedman, M. L., Griffin, M. L., Biegel, G., Roach, A., ... Saltzman, A. (2012). Integrating Mindfulness Training into K-12 Education: Fostering the Resilience of Teachers and Students. Mindfulness, 3(4), 291-307. https://doi.org/10.1007/s12671-012-0094-5

Miller, J. J., Fletcher, K., Ph, D., \& Kabat-zinn, J. (1995). Three-Year Follow-up and Clinical Implications of a Mindfulness Stress Reduction Intervention in the Treatment of Anxiety Disorders, 01634343(95), 192-200.

Murray-Harvey, R., T. Slee, P., Lawson, M. J., Silins, H., Banfield, G., \& Russell, A. (2000). Under stress: The concerns and coping strategies of teacher education students. European journal of teacher education, 23(1), 19-35.

O’Driscoll, M., Byrne, S., Mc Gillicuddy, A., Lambert, S., \& Sahm, L. J. (2017). The 
effects of mindfulness-based interventions for health and social care undergraduate students-a systematic review of the literature. Psychology, Health and Medicine, 22(7), 851-865. https://doi.org/10.1080/13548506.2017.1280178

Oberle, E., Schonert-Reichl, K. A., Lawlor, M. S., \& Thomson, K. C. (2012). Mindfulness and Inhibitory Control in Early Adolescence. Journal of Early Adolescence, 32(4), 565-588. https://doi.org/10.1177/0272431611403741

OECD. (2017). Health at a Glance 2017: OECD Indicators, OECD Publishing, Paris. Retrieved from http://dx.doi.org/10.1787/health_glance-2017-en.

Paquette, K. R., \& Rieg, S. A. (2016). Stressors and coping strategies through the lens of Early Childhood/Special Education pre-service teachers. Teaching and Teacher Education, 57, 51-58. https://doi.org/10.1016/j.tate.2016.03.009

Pfitzner-Eden, F. (2016). I feel less confident so I quit? Do true changes in teacher selfefficacy predict changes in preservice teachers' intention to quit their teaching degree? Teaching and Teacher Education, 55, 240-254. https://doi.org/10.1016/j.tate.2016.01.018

Reiser, J. E., \& McCarthy, C. J. (2018). Preliminary Investigation of a Stress Prevention and Mindfulness Group for Teachers. Journal for Specialists in Group Work, 43(1), 2-34. https://doi.org/10.1080/01933922.2017.1338811

Roeser, R. W., Skinner, E., Beers, J., \& Jennings, P. A. (2012). Mindfulness Training and Teachers' Professional Development: An Emerging Area of Research and Practice. Child Development Perspectives, 6(2), 167-173. https://doi.org/10.1111/j.1750-8606.2012.00238.x

Roeser, R. W., Schonert-reichl, K. A., Cullen, M., Wallace, L., Wilensky, R., Oberle, E., ... Harrison, J. (2013). Mindfulness Training and Reductions in Teacher Stress and Burnout: Results From Two Randomized, Waitlist-Control Field Trials, 
105(3), 787-804. https://doi.org/10.1037/a0032093

Roeser, R. W. (2016). Processes of teaching, learning, and transfer in mindfulnessbased interventions (MBIs) for teachers: A contemplative educational perspective. In Handbook of Mindfulness in Education (pp. 149-170). Springer, New York, NY.

Safran, J. D., \& Segal, Z. V. (1990). Interpersonal Process in Cognitive Therapy. New York: Basic Books.

Schonert-Reichl, K. A., \& Roeser, R. W. (2016). Mindfulness in education: Introduction and overview of the handbook. In Handbook of mindfulness in education (pp. 3-16). Springer, New York, NY.

Segal, Z. V., Teasdale, J. D., Williams, J. M., \& Gemar, M. C. (2002). The mindfulnessbased cognitive therapy adherence scale: Inter-rater reliability, adherence to protocol and treatment distinctiveness. Clinical Psychology and Psychotherapy, 9(2), 131-138. https://doi.org/10.1002/cpp.320

Segal, Z. V., Williams, J. M. G., \& Teasdale, J. D. (2002). Mindfulness-based cognitive therapy for depression: A new approach to preventing relapse. New York: Guilford Press.

Segal, Z. V., Williams, M., \& Teasdale, J. D. (2018). Mindfulness-based cognitive therapy for depression. Guilford Publications.

Shapiro SL, Schwartz GE, \& Bonner G. (1998). Effects of mindfulness-based stress reduction on medical and premedical students. Journal of Behavioral Medicine, 21(6), 581-599.

Shapiro, S. L., Carlson, L. E., Astin, J. A., \& Freedman, B. (2006). Mechanisms of mindfulness. Journal of clinical psychology, 62(3), 373-386.

Teasdale, J. D., Segal, Z., \& Williams, J. M. G. (1995). How does cognitive therapy 
prevent depressive relapse and why should attentional control (mindfulness) training help? Behaviour Research and therapy, 33(1), 25-39.

Teasdale, J. D. (1999). Metacognition, mindfulness and the modification of mood disorders, $155,146-155$.

Teasdale, J. D., Segal, Z. V., Williams, J. M. G., Ridgewaya, V. A., Soulsby, J. M., \& Lau, M. A. (2000). Prevention of relapse/recurrence in major depression by mindfulness-based cognitive therapy. Journal of Consulting and Clinical Psychology, 68(4), 615-623. https://doi.org/10.1037/0022-006X.68.4.615

Thera, N. (2005). The heart of buddhist meditation: Satipațthāna: A handbook of mental training based on the Buddha's way of mindfulness, with an anthology of relevent texts translated from the Pali and Sanskrit. Buddhist Publication Society.

Turner, S., Braine, M., \& College, T. (2016). Embedding wellbeing knowledge and practice into teacher education: building emotional resilience. Teacher Education Advanced Network (TEAN), 8(1), 67-82. Retrieved from https://dspace.lboro.ac.uk/dspace-jspui/bitstream/2134/19997/3/TEAN Jan 2016 paper final accepted version.pdf

Vesely, A. K., Saklofske, D. H., \& Nordstokke, D. W. (2014). EI training and preservice teacher wellbeing. Personality and Individual Differences, 65, 81-85. https://doi.org/10.1016/j.paid.2014.01.052

Williams, J. M. G., \& Kabat-Zinn, J. (2011). Mindfulness: diverse perspectives on its meaning, origins, and multiple applications at the intersection of science and dharma. $\quad$ Contemporary $\quad$ Buddhism, $12(1), \quad 1-18$. https://doi.org/10.1080/14639947.2011.564811

Zenner, C., Herrnleben-Kurz, S., \& Walach, H. (2014). Mindfulness-based interventions in schools-A systematic review and meta-analysis. Frontiers in 
Psychology, 5(JUN), 1-20. https://doi.org/10.3389/fpsyg.2014.00603

Zurlo, M. C., Pes, D., \& Capasso, R. (2013). Teacher stress questionnaire: validity and reliability study in italy 1, 490-517. https://doi.org/10.2466/03.16.PR0.113x23z9 